\title{
Cross Cultural Awareness Teaching in the English Literature Education
}

\author{
Hongyan Guan \\ Xi'an University, Xi'an Shaanxi, 710065, China
}

Keywords: English literature, Education, Cross-cultural awareness.

\begin{abstract}
With the advent of the world economic integration era, the education of English literature is no longer limited to the existing teaching system of Anglo-American literature, but extends to more countries that use English . This is the way and quality of English literature education Put forward new and higher requirements. Therefore, under the new situation, how to make good use of English literature education to cultivate students' cross-cultural awareness has drawn more and more attention from all walks of life. This article analyzes the relationship between English literature education and cross - cultural awareness teaching, expounds the important role of cultivating cross - cultural awareness in English literature education, and discusses some measures to cultivate cross - cultural awareness in English literature education.
\end{abstract}

\section{Introduction}

Nowadays, with the rapid development of society, economy, culture and science and technology in China, the implementation of English literature education has become more and more important. English literature course has always been a very important professional course in many subjects of English majors. In English literature course education, we must pay more attention to cultivating students' cross-cultural awareness. Cross-cultural awareness mainly refers to letting learners consciously grasp the relationship between other national cultures and their own cultures under the precondition of understanding and inheriting local cultures so as to realize the cultivation of cross-cultural awareness in English literature education. This requires students to fully grasp the background knowledge of various English literary works and to understand the content based on their cultural background so as to better understand the rich cultural meanings covered in English literary works. The cultivation of cross-cultural awareness in English literature education requires students not only to ensure that their culture is not infringed upon by the outside world, but also to learn other cultural contents related to it while learning English literature.

\section{Relationship between English Literature Education and Intercultural Awareness Teaching}

\section{Cross-cultural awareness teaching is a very important part of English literature education}

The literature of all countries in the world bear the great responsibility of reflecting their own culture and embodying their own national spirit and cultural connotation. English literature education also undertakes the tasks of carrying forward the customs, cultures and history of the countries where English is the mother tongue. Based on the cognition and study of English literature, we can further understand the economic, political and cultural aspects of a country. Therefore, to a certain extent, while studying English literature, it is also a process of cultivating and promoting one's own cross-cultural awareness.

\section{Cross - cultural awareness education can improve the effectiveness of English literature education}

The cultivation of cross-cultural awareness not only requires students to have a more comprehensive understanding of Anglo-American culture, but also needs to be able to proactively compare their culture with that of Anglo-American countries by comprehending their own culture and concluding the cultural similarities and differences between two countries, so as to enhance their own sensitivity 
to the culture. In the process of improving cross-cultural awareness, we can enable learners to grasp more vivid folk-custom culture embodied in English literature among the active learning of English literature so as to effectively enhance students' cognition of their own culture, so that Can more selectively absorb and learn from the culture of other countries, so as to remove the bad ones and make full use of comparative analysis. Furthermore, he improves the English teachers' effectiveness in English literature education.

\section{English literature education is an important channel for cultivating cross-cultural awareness}

Culture can not only be very fruitful in literary works, but also include the content of culture itself. For example, a mission literary work should describe the protagonist's identity, background and position when describing the protagonist's growth process in the work, and should also fully reflect the social and political conditions of the author's life , Economy, culture and so on. Of course, all kinds of characters in literary works will naturally reflect the economic and social development in the relevant era. Therefore, the English literature in the content of culture can imperceptibly cultivate students' cross-cultural awareness. In the meantime, learners who read English literature can use the online search function to gain knowledge and find out information about words that they do not understand, and students also indirectly receive two types of cultural conflicts.

\section{The important role of cultivating cross-cultural awareness in English literature education}

In English literature education, teachers should pay more attention to students' cross-cultural cognition, which plays an important role that students can not ignore in English majors. Nowadays, in the course of the development of social education in our country, relevant experts and relevant personnel struggling in the forefront of English literature education have summarized the effective cultivation of cross-cultural awareness into two parts. One is to improve learners' abilities in language comprehension. In English literature education, we should pay more attention to the improvement of learners 'cross-cultural awareness, which has a very obvious promotion and guarantee value in enhancing students' ability of comprehension of English literature. In the former English literature education, the teachers generally adhere to the traditional teaching methods and teaching concepts in our country. They pay too much attention to the teaching of grammar and article layout in English literature, but they neglect the teaching of English literature The potential cultural meanings in teaching and the creative background after literary works. The dull and single teaching method will greatly affect students' ability to apply knowledge in English literature. Second, continue to expand students' knowledge of English literature and education. In the English literature education should increase the background knowledge of English literature, so as to more effectively cultivate students in English literature education generated by cross-cultural awareness, in order to maximize students' enthusiasm for learning English. In the English literature education, the teachers can also be based on the implementation of the students with the English literature and cultural content appropriate to the cultural background knowledge, the implementation of more extended nature of teaching, in order to effectively and effectively develop students in English literature and education Of the cross-cultural awareness, and thus achieve greater literacy in English students.

\section{Some Measures to Cultivate Cross - cultural Consciousness in English Literature Education}

\section{Probe into the cultural difference between China and Western countries reasonably in teaching}

As soon as teachers of English Literature want to improve students' intercultural awareness better in English literature class teaching, we must constantly strengthen the teaching of students about the cultural differences between East and West. In view of the very different political, economic and cultural environments between our country and western countries, there are quite a lot of differences between our country and western countries in the content of literary education. In the teaching of 
English literature, we should continue to deepen the analysis of students' cultural differences between China and the West so as to help students to further integrate the excellent traditional culture of our country and the content of western culture to a great extent. Teachers undertaking the tasks of English literature education should conduct an in-depth study of the relevant knowledge of the cultural differences between China and the West in order to carry out targeted teaching. It must be emphasized that English literature education should be highly targeted whether in the teaching content or in the teaching method. Before the implementation of specific teaching, teachers should be included in our excellent traditional culture of English literature on cultural differences in teaching content.

\section{Probe into the in-depth contents of English literature reasonably in Teaching}

If classroom teachers want to improve students' cross-cultural awareness more effectively in English literature education, it is necessary to reasonably join the inquiry into the deep content of English literature in education. Under the premise of comprehensively helping and guiding students to carry out a comprehensive study of surface knowledge in English literature, they should further enhance students' potential abilities in English learning. The traditional culture involved in the knowledge of English literature has been well inherited in the long history. The members of the Western society have different behaviors and customs in different social backgrounds, Teaching can lead students to implement in-depth study of the deep cultural knowledge. In view of this, the teachers should be in the classroom to strengthen the student's deep level of English literature and cultural exploration, so as to effectively help students to further enrich the spiritual and cultural life.

\section{Continue to promote teaching students for culture empathy contents}

Reinforcing the teaching on cultural empathy is the main means by which teachers can effectively enhance students' intercultural awareness in the process of teaching English literature. Students' empathy for cultural empiricism will directly affect their ability to understand English literature, and thus whether their cross-cultural awareness can be formed in time. Due to the differences of geographical environment and social development, our country and western countries have produced very different cultures. When studying the relevant content of English literature, teachers should establish a platform for students to exchange and share foreign cultural knowledge so as to maximize the practical protection of the excellent traditional Chinese culture and the spread of Western culture And exchange. As a result, the ability of cultural empathy in the cross-cultural awareness of English literature education also has the ability to effectively play the role of exchange and sharing. Students can use their own intensification of learning awareness in cultural empathy and have a more accurate understanding of cross-cultural awareness in English literature so as to achieve continuous improvement in English literature learning.

\section{Give full play to the role of multimedia modern teaching methods}

Under the continuous promotion and influence of the development of modern education, China's English education has been put forward new requirements both in teaching methods and in teaching philosophy. The traditional way of teaching English literature has not been able to better adapt to the changing social needs of today. To join the classroom teachers in English literature teaching to better enhance students' intercultural learning ability, it should be reasonable in the classroom to introduce multimedia teaching methods, such as the English-speaking countries can be related to the local customs and culture of the use of pictures, video And other ways to play, so as to be more visual and three-dimensional display in front of the students, so as to achieve the smooth implementation of English literature education and promote students' awareness of cross-cultural continuous improvement. English literature education is the most crucial teaching content in English majors. Teachers in English literature more pay attention to the students in the field of cross-cultural awareness of the promotion, which is now our country English literature education in the development of new trends. Only when classroom teachers truly realize the important role of 
cross-cultural awareness training can they make effective use of effective measures to achieve a marked improvement in the quality of English literature education in our country.

\section{Use extracurricular activities to enhance students' cross - cultural consciousness in English literature}

English literature teaching time is quite limited. In order to better convey the knowledge of English literature to students and improve the quality of English literature teaching, teachers should be guided to use their spare time to enhance their intercultural awareness. For example, teachers may use some time in the classroom for For students to promote their understanding of outstanding works of English literature, so that students based on their own reality to implement selective reading of specific articles. At the same time, teachers can also recommend some of the more classic English-language movies for students. For example, students can listen to English musical works with rich cultural heritage and write students' sense of hearing. Teachers can also organize students to engage in various activities such as Western drama, film festivals and English corners. Based on the promotion of activities, students can exert their own initiative and effectively promote the dissemination of knowledge content related to English literature education so as to promote the integration of Chinese and Western cultures and further enhance their cross-cultural awareness.

\section{Improving the quality of teachers to enhance students' cross-cultural awareness}

Nowadays, some English teachers play a leading role in English literature teaching and thus play a guiding role. Therefore, the promotion of cross-cultural awareness in British literature also needs to cultivate students' cross-cultural awareness in English literature by improving their personal qualities. In order to improve the quality of teachers, we should focus on improving the professional quality of English literature teachers. At the same time, in order to further enhance the professional qualifications of teachers, teachers should earnestly grasp the professional quality of teachers and enhance their literary accomplishment. To further strengthen teachers' connotation and ideology of English literature is also an urgent need to fully understand. On the basis of having a detailed understanding of English literature, teachers should also give indirect answers to students based on the problems they have encountered in their studies. This is of great help to further their understanding of literary works and to master English literature Teaching effectiveness. Abstract The continuous improvement of teachers' professionalism is mainly due to the fact that teachers are overwhelming, and they should keep pace with the times in the teaching process. Thus effectively change the change of this traditional teaching methods, focusing on the cultivation of students' cultural qualities, from shallow to deep know that students learn and understand the content of English literature.

\section{Conclusions}

In short, cultivating students' cross-cultural awareness in English literature education has far-reaching implications for the development of learners' own learning abilities and is also a new requirement for English literature education after the development of the current era. Cultivating students' cross-cultural awareness in English literature education can comprehensively improve the actual results of English literature education and enable students to further enhance their cross-cultural awareness based on the comprehensive utilization of various kinds of information so as to be able to perform better Grasp the essence of English literature.

\section{Acknowledgements}

This paper is the stage results of the reform project of Xi'an University (Project Name: Innovative Research on Cultivating Intercultural Communication Competence of English Majors in Applied Universities. Project Number: JG2017017. Project number: JG2017017). 


\section{References}

[1] Li Jiao. On Cross-cultural Awareness in College English Education - Reflection on Teaching Practice and Countermeasures in Cultivating Cross-cultural Awareness, Journal of Hubei University of Economics (Humanities and Social Sciences), 2011(1).

[2] Xu Meng. Strategies for Cultivating Cross - cultural Awareness in English Literature Teaching, Technology Horizon, 2014(6).

[3] Tao Ranran. Intercultural Awareness Cultivation in English Literature Teaching, Journal of Qiqihar Teachers College, 2015(3).

[4] Gun Wenqin. Intercultural Awareness Cultivation in English Literature Teaching, Campus English, 2017(28). 